\title{
APPLICATION OF MAGNETIC METHODS TO THE STUDY OF THE STRAIN STATE OF NICKEL-BASED SUPERALLOYS
}

\author{
D. I. Davidov*, N. N. Stepanova, N. V. Kazantseva, M. B. Rigmant \\ M.N. Miheev Institute of Metal Physics, Ural Branch of the Russian Academy of Sciences, \\ 18 S. Kovalevskoy St., Ekaterinburg, Russian Federation \\ *Corresponding author. E-mail: davidov@imp.uran.ru; \\ address for correspondence: ul. S. Kovalevskoy, 18, Ekaterinburg, Russian Federation, 620990; \\ Tel.: +7 34337837 11; fax: +7 3433745244 .
}

Strain-induced magnetism is observed after severe high-temperature deformation in a gas turbine blade made from nickel-based superalloy. The appearance of ferromagnetic ordering in the initially paramagnetic alloy results from the formation of magnetic clusters inside the cuboids of the strengthening intermetallic phase $\left(\mathrm{Ni}_{3} \mathrm{Al}\right)$. The change in the values of magnetic susceptibility correlates with the change in the level of dynamic stresses and the number of stacking fault defects in different parts of the blade.

Keywords: nickel-based superalloy, magnetic properties, strain-induced magnetism, deformation, defects.

DOI: $10.17804 / 2410-9908.2017 .1 .006-012$

\section{Introduction}

It is known that deformation-induced ferromagnetism was observed in several intermetallic compounds, including $\mathrm{Ni}_{3} \mathrm{Al}$ [1-3]. The phenomenon is that an initially paramagnetic alloy becomes ferromagnetic at high degrees of deformation. According to modern notions, this phenomenon is not due to the formation of any new phase, and the term "magnetic cluster" is used to describe it. Superparamagnetic state is practically observed in alloys [4]. The annealing of deformed samples restores paramagnetic properties. All the cases of deformation-induced ferromagnetism reported in the literature are associated with cold deformation (e.g., cold rolling). It was previously shown by the authors of this work that strain-induced magnetism may occur after high-temperature deformation $[5,6]$.

The purpose of this paper is to attempt to understand the nature of the strain-induced magnetism phenomenon in Nickel superalloys after severe high-temperature deformation.

\section{Experiment}

Structural and magnetic tests were performed with an as-cast polycrystalline gas turbine blade made from the EP-800 alloy. The analyzed blade failed due to the impact from the fragments of another blade, which had collapsed during turbine operation with increased rotational speed and temperature raised to $880{ }^{\circ} \mathrm{C}$. The blade operation time was $9360 \mathrm{~h}$ (nearly 13 months). The initial state of the blade material was estimated by a sample after stepwise heat treatment according to the technical regulations [7] in four annealing stages: $1160{ }^{\circ} \mathrm{C}$ for $5 \mathrm{~h}, 1060{ }^{\circ} \mathrm{C}$ for $2 \mathrm{~h}, 1000{ }^{\circ} \mathrm{C}$ for $2 \mathrm{~h}$, $850{ }^{\circ} \mathrm{C}$ for $16 \mathrm{~h}$. Each stage was followed by air cooling.

The structural and magnetic studies were conducted at the collective centers of the Institute of Metal Physics. We used a JEM-200CX transmission electron microscope to study the fine structure and a JSM 6490 scanning electron microscope analyzer to determine the redistribution of the chemical elements.

The magnetic tests were performed at room temperature using an original nondestructive testing device designed for magnetic susceptibility measurements. The sensitivity of the device is $\pm 1 \cdot 10^{-4}$. The results were processed with the use of calibration samples. A Lake Shore 7407 vibrat- 
ing magnetometer was also used for magnetic measurements as an attested standard method for the verification of magnetic susceptibility measurements. The measurements were performed at a frequency of $82 \mathrm{~Hz}$. The vibration amplitude was $1.5 \mathrm{~mm}$; the relative measurement error was $1 \%$. The chemical composition of the investigated EP-800 superalloy is shown in tab. 1.

Table 1 - The chemical composition of the investigated nickel-based alloy, wt. \%

\begin{tabular}{|c|c|c|c|c|c|c|c|}
\hline $\mathrm{Cr}$ & $\mathrm{Mo}$ & $\mathrm{W}$ & $\mathrm{Al}$ & $\mathrm{Co}$ & $\mathrm{Nb}$ & $\mathrm{C}$ & $\mathrm{Fe}$ \\
\hline 12.2 & 6.0 & 7.4 & 4,5 & 9.5 & 2.2 & 0.05 & $\leq 1$ \\
\hline
\end{tabular}

\section{Results and discussion}

The study was conducted on the EP-800 nickel superalloy widely used in the Russian power industry [7]. The structure of EP-800 consists of a nickel solid solution, $40 \%$ of the strengthening $\gamma^{\prime}$-phase $\left(\mathrm{Ni}_{3} \mathrm{Al}\right)$, and a small amount of carbides $(2 \%)$. All the phases are paramagnetic at room temperature. The EP-800 blade retains its paramagnetic state within the entire standard operating period. The upper limit for the EP-800 blades is $900{ }^{\circ} \mathrm{C}$, with the working temperature of $800{ }^{\circ} \mathrm{C}$ (standard regime) and the warranty operation time of $27000 \mathrm{~h}$. We have not found information about any change in the magnetic behavior of the EP-800 superalloy after operation under standard conditions within the warranty period.

The main way of increasing the thermal efficiency and output power of the new-generation gas turbines is to increase the operating temperature and turbine rotation speed [8]. A turbine blade scheme is shown in fig. 1. It is well known [10] that dynamic stresses and temperature are maximal in the convex part of the turbine blade airfoil, at the site termed the suction side (airfoil back). Another place with high stresses is the leading edge of the airfoil. The blade lock is mainly affected by heat.

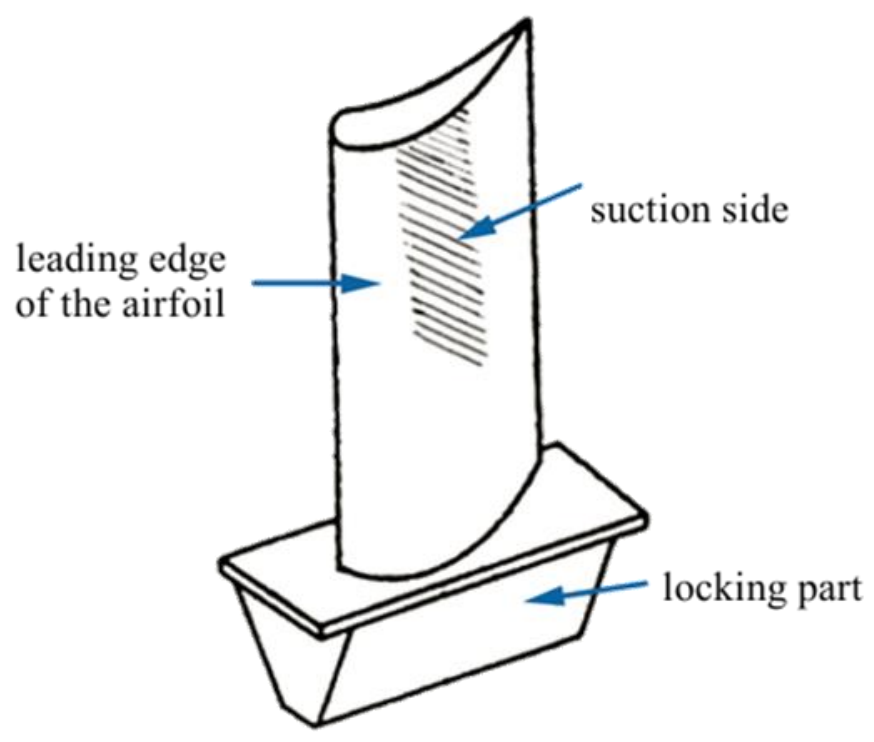

Fig. 1. Turbine blade scheme

The studied gas turbine blade was broken during operation by impact from the fragments of another blade. The results of magnetic measurements are shown in fig. 2 for the upper part of the blade airfoil. The initial sample has a low value of magnetic susceptibility, $\chi=4 \cdot 10^{-4}$. Our previous studies showed that in turbine blade areas with a high stress level there is an increase in magnetic susceptibility by two orders of magnitude during operation under forced conditions [5-6]. In our case, the values of magnetic susceptibility in the blade airfoil change from $20 \cdot 10^{-4}$ 
to $600 \cdot 10^{-4}$ (increase during operation). In the impact area, the magnetic susceptibility values increase to $1400 \cdot 10^{-4}$.

\subsection{The results of $X$-ray microanalysis}

The diffusion redistribution of the alloying elements was made on the airfoil cross section (fig. 2). The measurements were made at 12-16 points of the sample along scheme lines $1-3$ and processed statistically (see fig. 2). Tab. 2 shows the results of the chemical redistribution of the alloying elements in the superalloy affected by high temperature and stresses. The results demonstrate that the diffusion redistribution of the chemical elements inside the blade are suppressed significantly by alloying. Apparently, the magnetic effect is not associated with the redistribution of the chemical elements under deformation.

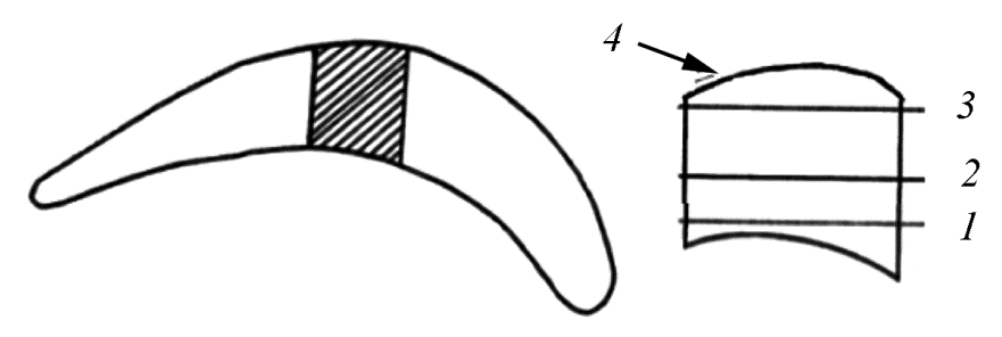

Fig. 2. A scheme of the cross section of the sample cut out from a blade airfoil

Table 2 - The chemical composition of different parts of a blade airfoil after operation

\begin{tabular}{|c|c|c|c|c|c|c|c|c|}
\hline No. & $\mathrm{Ni}$ & $\mathrm{Cr}$ & $\mathrm{Fe}$ & $\mathrm{Al}$ & $\mathrm{Mo}$ & $\mathrm{W}$ & $\mathrm{Co}$ & $\mathrm{Nb}$ \\
\hline 1 & 57.6 & 12.2 & 1.1 & 4.5 & 6.0 & 7.1 & 9.5 & 2.2 \\
\hline 2 & 56.7 & 11.9 & 1.0 & 4.2 & 6.8 & 7.7 & 9.1 & 2.3 \\
\hline 3 & 56.5 & 12.3 & 1.0 & 4.4 & 6.4 & 7.4 & 9.6 & 2.2 \\
\hline
\end{tabular}

The protective $\mathrm{Cr}_{2} \mathrm{O}_{3}$ oxide layer forms on the entire blade surface due to a high chromium content in the EP-800 superalloy. The $\mathrm{Cr}_{2} \mathrm{O}_{3}$ oxide is antiferromagnetic with a low value of magnetic susceptibility.

The only exception is the suction side. Table 3 presents the chemical composition of the oxide film in this place (see fig. 2, part 4). A local increase in iron concentration and a decrease in chromium concentration owing to diffusion under stress lead to the formation of the $\mathrm{Fe}_{3} \mathrm{O}_{4}$ ferromagnetic oxide.

Table 3 - The chemical composition of the oxide layer on the surface of the suction side

\begin{tabular}{|c|c|c|c|c|c|c|c|c|c|}
\hline No. & $\mathrm{Ni}$ & $\mathrm{Cr}$ & $\mathrm{O}$ & $\mathrm{Fe}$ & $\mathrm{Al}$ & $\mathrm{Mo}$ & $\mathrm{W}$ & $\mathrm{Co}$ & $\mathrm{Nb}$ \\
\hline 4 & 43.6 & 4.6 & 13.5 & 6.2 & 7.2 & 3.6 & 1.3 & 3.2 & 2.3 \\
\hline
\end{tabular}

The magnetic technique does not allow us to separate the formation of the surface ferromagnetic oxides and magnetic structure defects inside the blade material. However, both of these factors indicate the degradation of the alloy structure affected by high temperature.

\subsection{Measurements by a vibrating magnetometer}

Thin polished samples were cut out from the inner part of a blade airfoil (far from the oxide layer) to be used for magnetic measurements. The field dependence of magnetization $M(H)$ is presented in fig. 3. The magnetization curves for the lock and the initial sample are straight lines. The

Davidov V.I. et al. / Aplication of magnetic methods to the study of the strain state 
magnetization curves for the convex part of the blade foil and the impact area of the broken blade show saturation. The saturation magnetization value is higher in the blade airfoil than in the lock and the initial sample. The hysteresis loop is very narrow; this fact may suggest the superparamagnetic-like behavior (fig. 3 b). The hysteresis loop becomes wider as the saturation magnetization value increases. It may mean an increase in the number of magnetic clusters in the material.

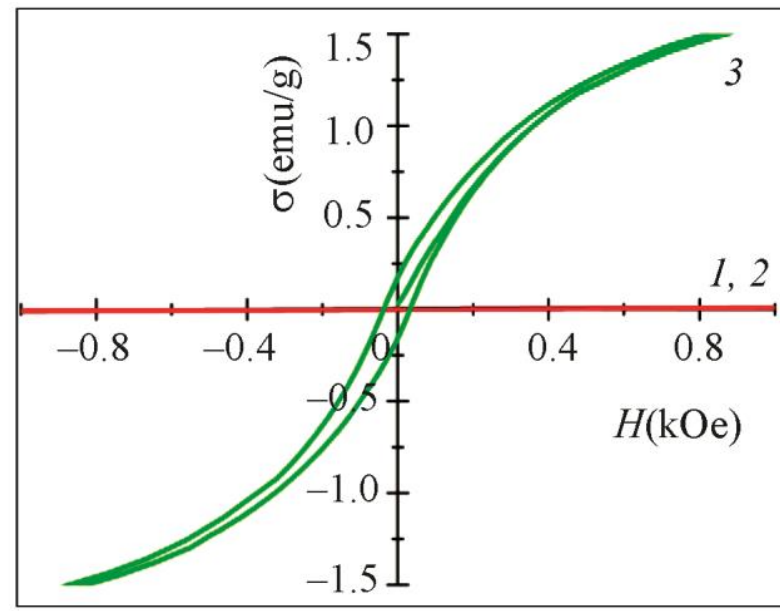

$a$

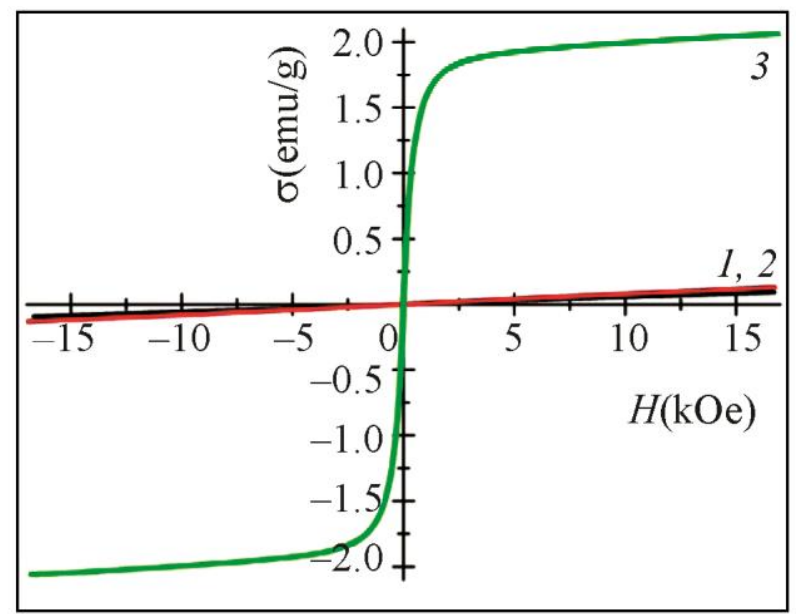

$b$

Fig. 3. The field dependence of blade magnetization $M(H)(a)$ and magnetization in weak fields $(b)$ : 1 - initial; 2 - lock; 3 - convex part of the airfoil

\subsection{Transmission electron microscopy study}

The results of transmission electron microscopy are presented in figs 4 and 5. The samples were cut out from the airfoil far from the oxide layer. No new phase formation was revealed in the inner part of the broken blade. The structure of the convex part of the airfoil shows a large number of defects in both the solid solution and the intermetallic $\gamma^{\prime}$-phase particles. In the area of impact, one can see a high defect density inside the $\gamma^{\prime}$-phase particles. The main type of defects inside the particles is intrinsic stacking faults. Since the intermetallic phase is well-ordered (has a superstructure), the defects belonging to it are termed superstructure stacking faults.

The structures of the locking part of the deformed blade and the initial sample are shown in fig. 6. The figure shows that the $\gamma^{\prime}$-cuboids are defectless inside.

According to data found in [9], the operation of a gas turbine blade under standard conditions cannot lead to the formation of stable defects inside the strengthening intermetallic phase particles. Under severe deformation, the formation of defects occurs inside the strengthening $\gamma^{\prime}$-phase cuboids. The formation of a stable defect complex inside the $\gamma^{\prime}$-phase indicates the softening of the intermetallic phase [10]. Planar structural defects may change the atomic positions in the intermetallic crystal lattice and promote a "cluster", a volume structural defect with ferromagnetic ordering [5].

The impression is that this cluster is not just the nanoscale area of the Nickel-based- $\gamma$ solid solution, especially since the $\gamma$-solid solution is paramagnetic. Note that severe shear deformation under high pressure leads to a decrease in the long-range order in the material as a whole and that it is accompanied by a decrease in the magnetic susceptibility of the alloy [11]. 
ittp.///ream-journal.or"]

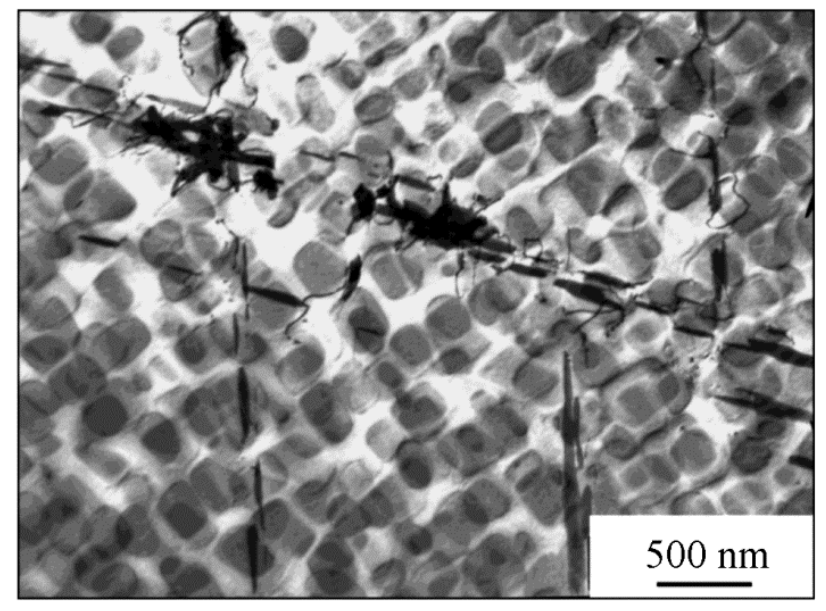

$a$

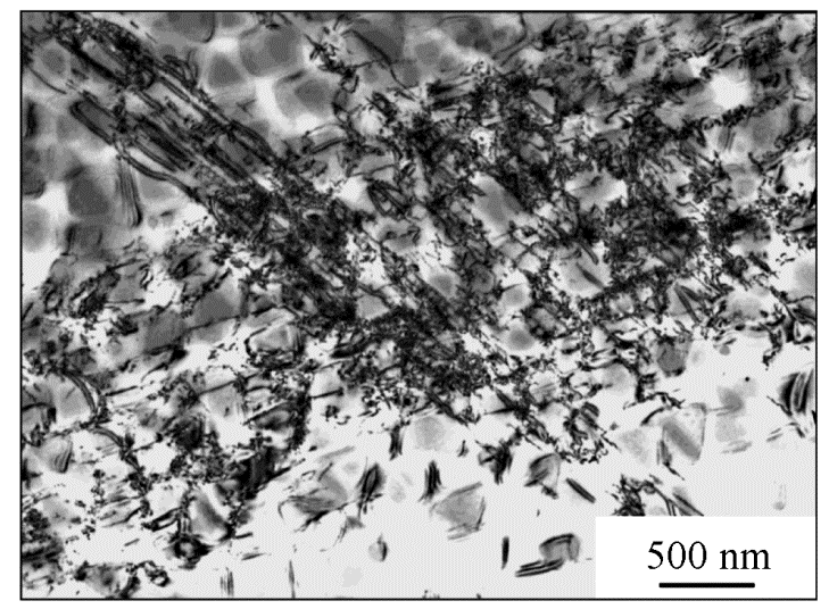

$b$

Fig. 4. The structure of different parts of a turbine blade after operation at $880{ }^{\circ} \mathrm{C}: a$ - stacking faults in the airfoil, a bright-field image; $b$ - high density of defects in the impact area

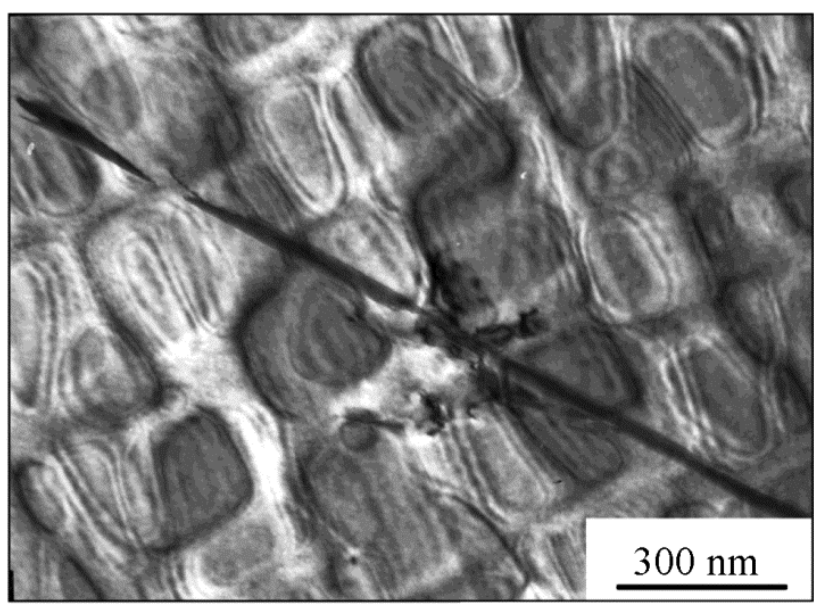

$a$

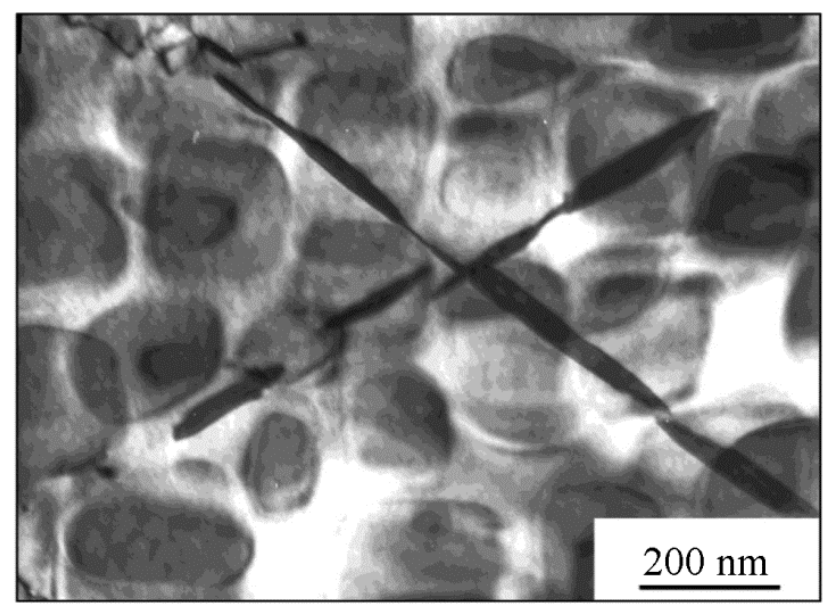

$b$

Fig. 5. Stacking fault defects inside the particles of the intermetallic $\gamma^{\prime}$-phase in the suction side

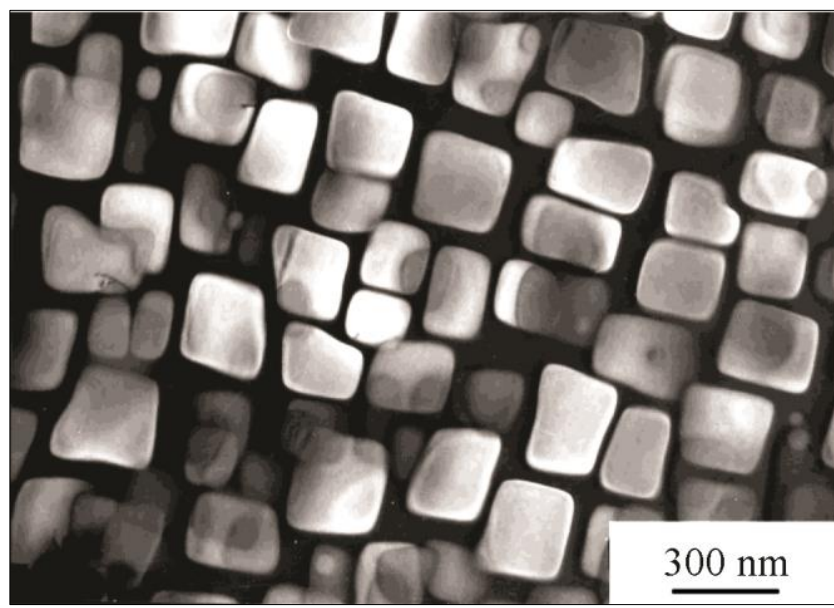

Fig. 6. The locking part of a broken blade, a dark-field image taken in the $\gamma^{\prime}$-phase reflection

Davidov V.I. et al. / Aplication of magnetic methods to the study of the strain state of nickel-based superalloys 
Apparently, the $L 1_{2}$-type ordering is destroyed inside the cluster, and a new order can be formed. One of the variants of cluster formation is the local rearrangement of the $L 1_{2}$ cubic superstructure into a long-period tetragonal lattice. This is possible if parallel stacking faults are regularly introduced between the planes of the cubic lattice. The simplest long-period tetragonal structure of this type is $\mathrm{DO}_{22}$.

This structural state is hard to study by diffraction methods, since in two directions the crystal lattice coincides with cubic. Therefore, special cross-sections of a tetragonal object are required to obtain a characteristic diffraction pattern.

In the case under study, microtwins are observed inside some cuboids in the impact area. The diffraction pattern of these objects cannot be interpreted as a diffraction pattern of FCC twinning, since the long-period phase with the $\mathrm{DO}_{22}$ superstructure has a tetragonal lattice with a parameter equal to approximately two parameters of the cubic phase. This assumption requires further structural validation. Note that the appearance of microtwins belonging to the long-period $\mathrm{DO}_{22}$ phase was previously observed [12] for the same Nickel-based superalloy after cold rolling.

\section{CONCLUSION}

Strain-induced magnetism is observed in a Nickel-based superalloy after high-temperature deformation. The appearance of ferromagnetic ordering in the initially paramagnetic alloy is considered as the formation of magnetic clusters in the material. Surface oxidation is an additional factor changing the magnetic susceptibility, and it occurs locally, in the area with a maximal stress level; however, oxidation is not the only reason for this phenomenon.

The cluster is not a fully disordered nanoscale area of the Nickel-based $\gamma$-solid solution. The phenomenon may be associated with superstructural stacking fault defects, all the more so since there is the following correlation: the higher the stress level and the greater the magnetic effect - the more stacking fault defects in a given sample area.

The cluster can be considered as a microscopic area with a long-period structure, for example, with the $\mathrm{DO}_{22}$ superlattice. We can suggest that the formation of this long-period phase during deformation is determined by the ordering of the stacking fault defects in the crystal, they being self-arranged during relaxation.

The highly sensitive portative device allows one to measure the stray magnetic fields of local magnetic areas in the material. This technique detects a low content of ferromagnetic inclusions in a paramagnetic matrix. The device can be used successfully both for a quick diagnostics of gas turbine blade damage and for scientific research.

\section{ACKNOWLEDGMENTS}

The research was done within the state assignment of FASO of Russia (theme "Crystal" No. 01201463333) supported in part by UB RAS project No. 15-17-2-11.

\section{REFERENCES}

1. Zeng Q., Baker I. The effect of local versus bulk disorder on the magnetic behavior of stoichiometric $\mathrm{Ni}_{3} \mathrm{Al}$. Intermetallics, 2007, vol. 15, iss.3, pp. 419-427. DOI: 10.1016/j.intermet.2006.08.010.

2. Takahashi S., Ikeda K.J. The influence of coldworking on magnetic properties in $\mathrm{Ni}_{3} \mathrm{Al}$. Journal of Physics F: Metal Physics, 1983, vol. 13, pp. 2169-2174.

3. Yasuda H.Yu., Yanai T., Umakoshi Yu., Takahashi S. Fatigue behavior and magnetic property of $\mathrm{Ni}_{3}(\mathrm{Al}, \mathrm{Ti})$ single crystals deformed at high temperatures. Scripta Materialia, 2001, vol. 44, pp. 581-586.

4. Baker I., Wu D. Strain-induced ferromagnetism in $L 1_{2}$ compounds. TSM letters, 2005, vol. 2, pp. 57-58. 
5. Stepanova N.N., Davydov D.I., Nichipuruk A.P., Rigmant M.B., Kazantseva N.V., Vinogradova N.I., Pirogov A.N., Romanov E.P. The structure and magnetic properties of a heatresistant nickel-base alloy after a high-temperature deformation. The Physics of Metals and Metallography, 2011, vol. 112, no. 3, pp. 309-317.

DOI: $10.1134 / \mathrm{S} 0031918 X 11030288$.

6. Stepanova N.N., Rigmant M.B., Davidov D.I., Shishkin D.A. Analyze of magnetic properties and structure in Nickel gas turbine blade after operation at forced regime. Proceedings of Academics World 10th International Conference, Istanbul, Turkey, 11 ${ }^{\text {th }}$ December, 2015, pp. 1-4. ISBN 978-93-85832-62-8.

7. Maslenkov S.B. Zharoprochnye stali $i$ splavy [Heat-resistant steels and alloys. Reference book]. M., Metallurgiya, 1983, 192 p. (In Russian).

8. Tsukagoshi K., Muyama A., Masada J., Iwasaki Y., Ito E. Operating status of uprating gas turbines and future trend of gas turbine development. Mitsubishi Heavy Industries. Technical Review, 2007, vol. 44, no. 4, pp. 1-6.

9. Umakoshi Y., Yasuda H.Y. Observation of lattice defects and nondestructive evaluation of fatigue life in $\mathrm{FeAl}$ and $\mathrm{Ni}_{3} \mathrm{Al}$ based alloy by means of magnetic measurement. Materials Science Forum, 2006, vol. 512, pp. 13-18.

DOI: 10.4028/www.scientific.net/MSF.512.13.

10. Jahangiri M.R., Abedini M. Effect of long time service exposure on microstructure and mechanical properties of gas turbine vanes made of IN939 alloy. Materials \& Design, 2014, vol. 64, pp. 588-600. DOI: 10.1016/j.matdes.2014.08.035.

11. Kazantseva N.V., Pilyugin V.P., Zavalishin V.A., Stepanova N.N. Effect of a nanosized state on the magnetic properties of $\mathrm{Ni}_{3}(\mathrm{Al}, \mathrm{Fe})$ and $\mathrm{Ni}_{3}(\mathrm{Al}, \mathrm{Co})$. The Physics of Metals and Metallography, 2014, vol. 115, no. 3, pp. 243-247.

12. Bhattacharya B., Ray R.K. Deformation behavior of a $\mathrm{Ni}_{3} \mathrm{Al}$ (B, $\mathrm{Zr}$ ) alloy during cold rolling: Part II. Microstructural and textural changes. Metallurgical and Materials Transactions A, 2000, vol. 31 (12), pp. 3011-3021. DOI: 10.1007/s11661-000-0080-8. 